\title{
A Downstream Voyage with Mercury
}

\author{
Gary H. Heinz ${ }^{1}$
}

Received: 2 August 2016/ Accepted: 16 August 2016/Published online: 25 August 2016

(C) Springer Science+Business Media New York 2016

As I look back on my paper, "Effects of Low Dietary Levels of Methyl Mercury on Mallard Reproduction," published in 1974 in the Bulletin of Environmental Contamination and Toxicology, a thought sticks in my mind. I realize just how much my mercury research was not unlike a leaf in a stream, carried this way and that, sometimes stalled in an eddy, restarted, and carried downstream at a pace and path that was not completely under my control. I was hired in 1969 by the Patuxent Wildlife Research Center to study the effects of environmental pollutants on the behavior of wildlife. A colleague was conducting a study on the reproductive effects of methylmercury on mallards (Anas platyrhynchos), and he offered to give me some of the ducklings. I conducted a pilot study, testing how readily ducklings approached a tape-recorded maternal call. Sample sizes were small, but the results suggested that ducklings from mercury-treated parents behaved differently than controls. That's how I got into mercury research-pretty much by chance.

The next year, I purchased my own adult mallards and fed them a control diet, a diet containing $0.5 \mu \mathrm{g} / \mathrm{g}$ mercury (as methylmercury dicyandiamide), or a diet containing $3 \mu \mathrm{g} / \mathrm{g}$ mercury (Heinz 1974). My goal was to put the ducklings from these breeding adults through my behavioral tests, but I noticed that some of the ducklings from parents fed $3 \mu \mathrm{g} / \mathrm{g}$ mercury staggered about and later died. Dr. Louis Locke, a pathologist at our center, discovered that methylmercury, transferred from the mother to her

Gary H. Heinz

gheinz@usgs.gov

1 Patuxent Wildlife Research Center, U.S. Geological Survey, c/o BARC-East, Building 308, 10300 Baltimore Avenue, Beltsville, MD 20705, USA eggs, had caused lesions in the brains of the ducklings (Heinz and Locke 1976). The following year, I fed the same female mallards the diets they had received the year before. As was the case in the first year, $3 \mu \mathrm{g} / \mathrm{g}$ mercury in the adult diet resulted in a decrease in duckling survival (Heinz 1976).

As I was thinking about what to do next, I happened upon a few papers related to multi-generation effects of contaminants on wildlife. I got the idea that it would be interesting to feed the offspring of the mercury-dosed adults the same concentration of mercury as their parents had been fed, and see if any harmful effects, not seen in the first generation, might surface in the second generation. Having shown pretty conclusively that $3 \mu \mathrm{g} / \mathrm{g}$ mercury fed to adults was harmful to their ducklings, in this second generation study I focused on the controls and birds in the $0.5 \mu \mathrm{g} / \mathrm{g}$ mercury group. The results demonstrated that second-generation females fed $0.5 \mu \mathrm{g} / \mathrm{g}$ mercury did not produce as many 1-week-old ducklings as did controls. Based on these exciting second generation results, I talked to my supervisor, Dr. Lucille Stickel, asking if it was okay to begin a third generation study. She was not happy with this idea. She said something to the effect: Gary, we have a lot of chemicals that need studying and we can't just keep working on the same one. But I must have had a sorrowful look on my face, because she finally said, "Okay but this is your last mercury study." And it was-for a while.

That "last" study (Heinz 1979) turned out to be a fairly influential one because the results were used to set regulatory guidelines for methylmercury in water. In this 1979 paper, I reported that $0.5 \mu \mathrm{g} / \mathrm{g}$ mercury in the diet of breeding mallards resulted in about $0.8 \mu \mathrm{g} / \mathrm{g}$ mercury, wetweight, in eggs, and that this very low concentration in eggs harmed reproduction. I remember how the editor of the Journal of Wildlife Management questioned how many 
papers ("the second-year," "the second-generation," "the third-generation") were needed in his journal to cover this subject! But the editor grudgingly published all of the papers. I am surprised that, to this day, that value of $0.8 \mu \mathrm{g} /$ $\mathrm{g}$ mercury in bird eggs is used as a cut-off point for reproductive harm in birds.

After publishing that 1979 study, adhering to the admonitions of my boss, I drifted, like that leaf in a stream I talked about earlier, away from mercury research. I found out that, as time goes by, contaminants such as mercury rise and fall in popularity for study and funding. For many years, I kind of floated along, doing lab and field studies on a great variety of contaminants, all interesting, but none having the singular focus of my earlier mercury work. Then, a very well-funded research effort was initiated at our research center on selenium. And after that, another large effort was started on lead poisoning. My research career was gliding smoothly downstream, pretty much free of getting caught up in swirling eddies. I published quite a few papers on each of these two contaminants. This retrospective is supposed to be about my mercury research and how it all got started with that 1974 paper in the Bulletin, but I mention the selenium, lead, and other contaminant work because they constituted my biggest body of research. My early and late mercury efforts were like bookends to what happened in the middle of my 43-yearlong career.

The last bookend fell into place around 2000 when questions about mercury pollution from past gold mining activities in California resulted in funding for mercury research with birds. The best mercury research I ever conducted would occur during the next decade or so. The experimental designs I used in these last mercury studies were superior to those used in the 1974 Bulletin of Environmental Contamination and Toxicology paper. However, in spite of their superiority, the 1979 3-generation mercury paper, which had evolved directly from the 1974 Bulletin paper, seems to this day to carry the most weight of the over two dozen mercury papers I've published. This 1979 paper has been cited 343 times (according to Google Search) and has been cited at least once in every year from 1979 to 2016. The 1974 Bulletin of Environmental
Contamination and Toxicology paper has been cited 119 times, which is respectable in itself.

As I look back on the 1974 paper, I think about it in different ways. I think about it as the beginning of my decades' long research 'battle' with mercury. And I also think about it just in terms of being so many years ago, a whole research lifetime ago. When I began planning for the 1974 Bulletin study, I was 27 years old and, frankly, I didn't know too much about the harm of mercury contamination to birds. Writing this little essay now, all I have to do is reverse those two numbers ( 2 and 7 ) to come up with my current age: 72 . I realize I still only understand a fraction of what there is to know about mercury contamination and birds. Ironically, the initial behavioral findings I got in that pilot study that prompted me to conduct the 1974 study proved to be a statistical anomaly, contradicted by findings when I tested thousands of ducklings in bigger studies. So, everything got started by some false, chance results.

In science, we like to think we are in charge, directing the course of our long-term studies and interests, but I believe we are often at the mercy of our everyday work life: changing budgets, changing assignments from our boss, and just luck. Hey-science is dignified, logical, and objective, but life can be unpredictable, mysterious, and ridiculous. And life generally trumps science. More than we like to think, our career is like a leaf in a stream, carried this way and that by forces other than ourselves-but that's okay. At least it was for me.

\section{References}

Heinz G (1974) Effects of low dietary levels of methyl mercury on mallard reproduction. Bull Environ Contam Toxicol 11:386-392

Heinz GH (1976) Second-year feeding effects on mallard reproduction and duckling behavior. J Wildl Manage 40:82-90

Heinz GH (1979) Methylmercury: reproductive and behavioral effects on three generations of mallard ducks. J Wildl Manage 43:394-401

Heinz GH, Locke LN (1976) Brain lesions in mallard ducklings from parents fed methylmercury. Avian Dis 20:9-17 